\title{
SARS-COV-2 INFECTION IN A PATIENT WITH PAROXYSMAL NOCTURNAL HAEMOGLOBINURIA (PNH) TREATED WITH RAVULIZUMAB: A CASE REPORT
}

\section{INFECCIÓN POR SARS-COV-2 EN UN PACIENTE CON HEMOGLOBINURIA PAROXÍSTICA NOCTURNA (HPN) EN TRATAMIENTO CON RAVULIZUMAB: A RAÍZ DE UN CASO CLÍNICO}

\author{
Pablo Estival'; Blanca Colás'; Yang Dai' F. Ataulfo Gonzalez ${ }^{1}$ \\ 'Hospital Clinico Universitario San Carlos, Department of Hematology, The Clínic Institute of Hematological and \\ Oncological Diseases, Madrid, Spain \\ ${ }^{2}$ Alexion Pharmaceuticals, Inc., Boston, MA
}

Keywords:
Ravulizumab;
Complement
C5 inhibitor;
paroxysmal
nocturnal
hemoglobinuria;
PNH;
Covid-19;
SARS-CoV-19.
Palabras clave:
Ravulizumab;
Inhibidores de C5;
Hemoglobinuria
paroxística nocturna;
HPN;
COVID-19;
SARS-CoV-2.

Keywords:

C5 inhibitor

paroxysmal

hemoglobinuria;

PNH

Covid-19;

Inhibidores de $\mathrm{C}$;

paroxística nocturna;

COVID-19;

SARS-COV-2.

\begin{abstract}
The clinical course of a Paroxysmal Nocturnal Hemoglobinuria (PNH) patient receiving treatment with terminal complement by ravulizumab and SARS-CoV2 infection is described.

The treatment commenced in January 2016 showing adequate tolerance and symptom resolution.

In April 2020 an episode of breakthrough hemolysis is observed. Chest X-Ray revealed a right infection lobar infiltrate with SARS-CoV-2 positive PCR. The patient was afebril with normal oxygen saturation. He did not require standard disease treatment and presented eventual resolution, developing only mild symptoms.

Neither PNH nor ravulizumab treatment seem to influence susceptibility to Covid-19 infection. It is possible that razulizumab, a complement inhibitor, may have played a beneficial role in the favorable clinical development.
\end{abstract}

\section{Resumen}

Se describe el curso clínico de un paciente diagnosticado de infección por SARS-CoV-2 en tratamiento con un inhibidor terminal del complemento (Ravulizumab; ensayo clínico ALXN 1210) para Hemoglobinuria Paroxística Nocturna (HPN), que comenzó en Enero de 2016 con buena tolerancia y resolución de los síntomas.

En abril del 2020, durante una consulta de seguimiento dentro del ensayo, el paciente presenta un episodio de hemólisis aguda. La radiografía de tórax mostró un infiltrado pulmonar en lóbulo inferior derecho. Se efectuó una PCR de SARS-COV2 que resultó positiva.

El paciente estaba afebril, sin signos de infección o afectación respiratoria. Presentó resolución espontánea, desarrollando únicamente sintomatología leve. No requirió tratamiento habitual para la infección por coronavirus.

Tanto el HPN como el ravulizumab parecen no tener influencia en la susceptibilidad individual a la infección por SARS-COV2. Es posible que el ravulizumab (un inhibidor del complemento) juegue un papel beneficioso en el desarrollo de un curso clínico favorable.

\section{INTRODUCTION}

SARS-CoV2 infection has implied a major challenge for medical community, primarily for Hematology. In fact, actual evidence of the disease in hematological patients, usually immunocompromise, is primarily insufficient, and they mortality approach $30 \%(1)$.

$\mathrm{PNH}$ is a clonal stem cell hematopoietic disease characterized by chronic intravascular hemolysis and increased risk of thrombosis. This is due to acquired somatic mutation which impairs the biosynthesis of the glycosylphosphatidylinositol (GPI) anchor, and as a consequence all GPI-linked proteins are not expressed on affected hematopoietic stem cells and their mature progeny blood cells. Among the missing GPI-linked proteins, the lack of the two complement inhibitors, MIRL (CD59) and DAF (CD55), makes red blood cells more susceptible to lytic action by the complement system. Nowadays, monoclonal antibodies against complement (like anti C5 therapies eculizumab 
or ravulizumab) are gold standard treatments for this disease by inhibiting the formation of the membrane attack complex (MAC) (2). Herein, we will delve into the evolution of a $\mathrm{PNH}$ patient under ravulizumab treatment with SARS-CoV2 infection.

\section{CASE REPORT}

A 43 year-old-men with diagnosis of PNH in April 2014 , presenting acute renal failure with macrohematuria and proteinuria. In the laboratory tests, Hemoglobin $(\mathrm{Hb})$ was $9.9 \mathrm{~g} / \mathrm{dL}$ and lactate dehydrogenase $(\mathrm{LDH})$ was $6296 \mathrm{U} / \mathrm{L}$. By flow cytometry a decrease in expression of antigens CD16, CD24 and Aerolysin FLAERS in $85 \%$ of neutrophils and $87 \%$ of monocytes (CD14 and Aerolysin FLAER) was detected. He was reporting asthenia, retrosternal pain, dysphagia, odynophagia, diffuse abdominal pain, erectile disfunction and dark urine.
He returned on April 8, 2020, for regular dosing with ravulizumab. On this day, laboratory measures from the patient showed evidence of breakthrough hemolysis (Table 1). A flow cytometry test was performed (Figure 1). Upon questioning, the patient described mild catarrhal symptoms the previous week. He reported dry cough with no fever nor any other infectious symptoms. The patient presented in good general condition, afebrile, with oxygen saturation of $100 \%$. Two units of packed red blood cell concentrates were transfused, and antibiotic treatment with Cefixime and Ciprofloxacin was prescribed, as well as antithrombotic prophylaxis with Enoxaparin. Due to suspected SARS-CoV-2 infection, a nasopharyngeal exudate sample was collected, with a positive test result.

The patient remained asymptomatic, without any new symptom of infection or hemolysis. The chest X-ray on April 13, demonstrated clear improvement of infiltrates in right inferior lobe without the appearance of new consolidations (Figure 2).
A.

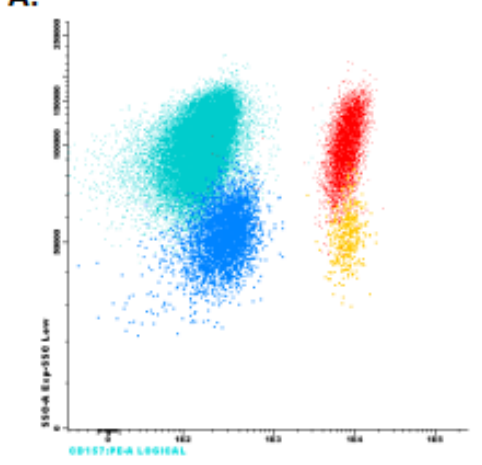

B.

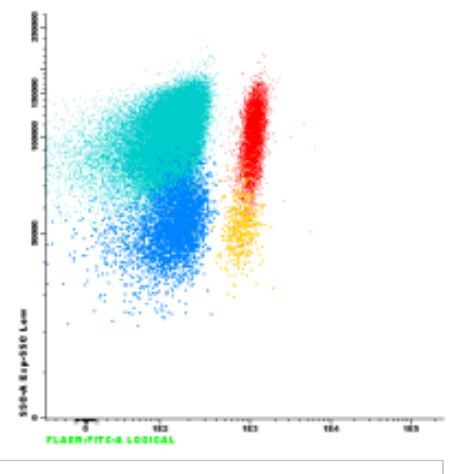

C.

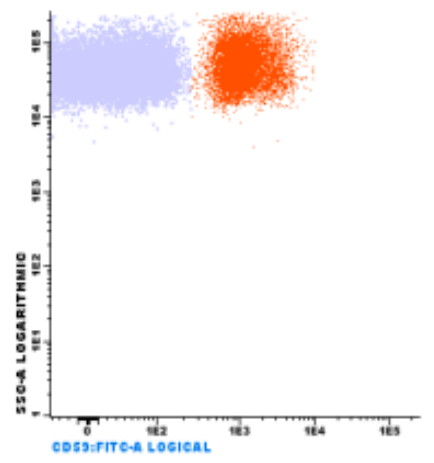

Figure 1. Flow cytometry. A: Display of CD157 in granulocyte population (GPI+ red cells, GPI-cyan cells) and in monocyte population (GPI+ yellow cells, GPI- blue cells). B: Display of FLAER in granulocyte population (GPI+ red cells, GPI-cyan cells) and in monocyte population (GPI+ yellow cells, GPI- blue cells). C: Display of CD59 in red blood cells (GPI+ orange cells, GPI- gray cells).

In January 2016, the patient was referred to our Hospital's Hematology Department for evaluation of anti-C5 treatment. The first dose of ravulizumab ( ALXN-1210-PNH-201 clinical trial) was received on January 20th, 2016 with good tolerance and resulted in the disappearance of asthenia and other symptoms. Since the initiation of ravulizumab treatment, the patient has maintained $\mathrm{Hb}$ values over $13 \mathrm{~g} / \mathrm{dL}$, with LDH values always under $600 \mathrm{U} / \mathrm{L}$, and experienced only one episode of breakthrough hemolysis, in the context of influenza A infection, with elevated LDH levels up to $1554 \mathrm{U} / \mathrm{L}$, and maintained acceptable values of $\mathrm{Hb}(11.1 \mathrm{~g} / \mathrm{dL})$.
The analysis showed a clear decrease in the acute phase reactants, with normal values of C-reactive protein and procalcitonin, without decrease in the hemoglobin levels (Table I).

Upon examination on the 27th of April, the patient continued to be asymptomatic. In the chest X-Ray, the infiltrates had disappeared (Figure 2).

The hemoglobin levels had increased, approaching normal values. The values of fibrinogen, $\mathrm{D}$-dimer, $\mathrm{LDH}$, and ferritin were within the normal range (table 1). 
Table 1.- LABORATORY TEST RESULTS

\begin{tabular}{|c|c|c|c|c|c|}
\hline & $\begin{array}{l}\text { Normal } \\
\text { Range }\end{array}$ & $\begin{array}{l}\text { 12th } \\
\text { February } \\
2020\end{array}$ & $\begin{array}{l}\text { 08th April } \\
2020\end{array}$ & $\begin{array}{l}\text { 13th April } \\
2020\end{array}$ & $\begin{array}{l}\text { 27th April } \\
2020\end{array}$ \\
\hline Hemoglobin (g/dL) & $13.5-18$ & 14.3 & 7.6 & 11.8 & 14.2 \\
\hline Hematocrit (\%) & $42-55$ & 43 & 23.4 & 35.2 & 43.5 \\
\hline $\operatorname{MCV}(\mathbf{f L})$ & $78-100$ & 96.8 & 97.1 & 95.7 & 97.5 \\
\hline Reticulocytes (\%) & $0.5-2$ & 1.6 & 7.97 & & \\
\hline $\mathrm{WBC}\left(1 \times 10^{\wedge} 3 / \mathrm{uL}\right)$ & $4-10.5$ & 4.2 & 5.5 & 3.8 & 6.6 \\
\hline Neutrophils $\left(1 \times 10^{\wedge} 3 / \mathrm{uL}\right)$ & $1.5-6.6$ & 1.9 & 2.7 & 1.5 & 3.1 \\
\hline Lymphocytes $\left(1 \times 10^{\wedge} 3 / \mathrm{uL}\right)$ & $1.5-3.5$ & 1.9 & 2.3 & 1.7 & 2.9 \\
\hline Monocytes $\left(1 \times 10^{\wedge} 3 / \mathrm{uL}\right)$ & $0.1-1$ & 0.4 & 0.5 & 0.4 & 0.6 \\
\hline Platelets (1x10^3/uL) & $150-450$ & 293.0 & 582.0 & 500.0 & 338.0 \\
\hline PT(s) & $10-14$ & & 13.1 & 12.4 & 11.8 \\
\hline APTT(s) & $23.5-39.2$ & & 34.7 & 34.1 & 32.2 \\
\hline Fibrinogen $(\mathrm{mg} / \mathrm{dL})$ & $150-450$ & & 683.0 & 474.0 & 250.0 \\
\hline D-Dimer(ng/mL) & $0.1-500$ & & 850.0 & 455.0 & 174.0 \\
\hline CRP (mg/dL) & $0.1-0.5$ & & 5.90 & 0.5 & $<0.29$ \\
\hline Procalcitonin (ng/mL) & & & 0.05 & 0.09 & 0.04 \\
\hline Ferritin (ng/mL) & $30-350$ & & 797.7 & 640.4 & 369.5 \\
\hline Haptoglobin (mg/dL) & $30-200$ & & 98.9 & 87.3 & 74.3 \\
\hline $\begin{array}{l}\text { Alpha-1-acid glycoprotein } \\
(\mathrm{mg} / \mathrm{dL})\end{array}$ & $50-120$ & & 190.0 & 129 & \\
\hline Glucose (mg/dL) & $60-100$ & 93 & 98 & 98 & 88 \\
\hline Urea $(\mathrm{mg} / \mathrm{mL})$ & $15-50$ & 39 & 42 & 48 & 44 \\
\hline Creatinine (mg/dL) & $0.67-1.17$ & 1.06 & 0.91 & 0.99 & $1.03^{\star}$ \\
\hline $\mathrm{CrC}(\mathrm{mL} / \mathrm{min})$ & $60-140$ & 86.1 & 103.6 & 93.6 & $88.5^{\star}$ \\
\hline $\mathrm{Na}(\mathrm{mmol} / \mathrm{L})$ & $135-145$ & 136 & 139 & 137 & 139 \\
\hline $\mathrm{K}(\mathrm{mmol} / \mathrm{L})$ & $3.4-5.5$ & 4.0 & 4.2 & 4.6 & 4.1 \\
\hline LDH (U/L) & $240-480$ & 618 & 811 & 618 & 484 \\
\hline
\end{tabular}

*This value was obtained on 11th May 

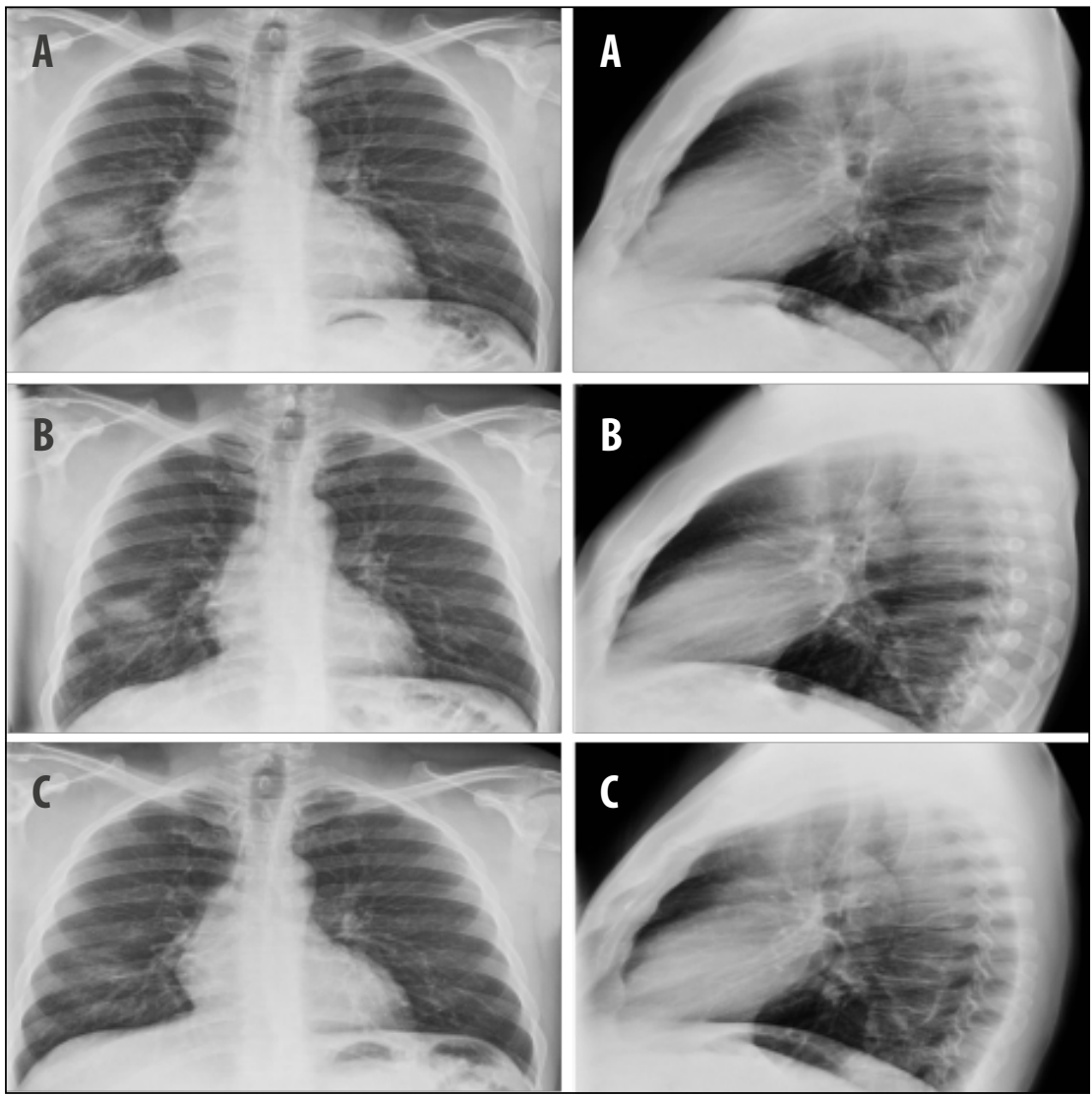

Figure 2. Evolution of the patient's lower-right lobar infiltrate in 3 consecutive $P A$ and lateral radiographies. A: 08th April 2020. B: 13th April 2020. C: 27th April 2020.

\section{DISCUSSION}

SARS-CoV2 infection presents a variable clinical course, while most subjects with SARS-CoV-2 develop mild to moderate symptoms, others contract profound seemingly unchecked inflammatory responses, leading to acute lung injury and hypoxemic respiratory failure, the most common cause of death (3). The foundation to these diverse clinical manifestations is still unknown, and many of the usable scientific hypotheses came from previous studies from MERS and SARS coronavirus outbreaks.

Available evidence suggests that SARS-CoV-2 disease is characterized by an excessive inflammatory response, implying an activation of innate immune pathways, with a cytokine storm syndrome development, resembling secondary hemophagocytic lymphohistiocytosis (sHLH) (4). Likewise, there is also pathological activation of thrombin. Multiple thrombotic episodes had been observed, from thrombotic microangiopathy and disseminate intravascular coagulation, to thromboembolism (5).

The complement system is a vital element of innate immune response. It works by recognizing molecular patterns present in pathogens and autologous apoptotic cell debris. Its final target is to promote the opsonization and direct lysis of these cells. There is accumulating evidence suggesting that the overactivation of the complement system caused by coronavirus may have a major role in the pathogenesis of ARDS (6). Furthermore, as studies suggest that lung damage caused by SARS-CoV-2 alone is not responsible for all pathological changes associated with typical ARDS. Significant deposits of complement's MAC, C4d and mannose binding lectin (MBL)-associated protease, as well as co-localization of SARS-CoV-2 spike glycoprotein were shown in skin and lung microvasculatures of SARS-CoV-2 patients. These findings suggest that in some critical patients, SARS-CoV-2 may involve catastrophic thrombotic microvascular injury, mediated by activation of the complement alternative pathway and lectin pathway.

Therefore, available evidence supports the important role of the complement system in the development of pulmonary damage associated to SARS-CoV-2. Diurno et al reported their experience with four patients admitted in ICU with SARS-CoV-2 severe pneumonia, who were treated with eculizumab. All of them successfully recovered. None of these patients carried a diagnosis of PNH (7). Giudice et al recently reported a study with seven patients treated with the novel combination of ruxolitinib and eculizumab compared to ten patients with the best available therapy. Patients treated with the combination showed significant improvements in respiratory symptoms and radiographic pulmonary lesions and decrease in circulating D-dimer levels compared to the best available therapy group (8). 
Conversely, these treatments interfere with the innate immune response by blocking complement activation, which facilitates certain infections, particularly those caused by encapsulated bacteria. In fact, when receiving eculizumab or ravulizumab treatment, Neisseria meningitidis vaccination is compulsory, and prophylactic antibiotic therapy is recommendable (9). On the other hand, higher susceptibility to viral infections has not been shown to be associated with complement blockade, but an increase in upper respiratory tract infection has been reported in these patients (9).

In spite of being a high-risk subject, our patient developed only mild symptoms, and eventual clinical resolution, not needing standard SARS-CoV-2 disease treatment, nor any other special care. It is possible that ravulizumab treatment played a beneficial role in his favorable development, in the same way as described by Diurno and Giudice $(7,8)$. Kulasekararaj reported 4 PNH patients with SARS-CoV-2 infection whom 2 of them were treated with C5 blockade (one under ravulizumab and the other one with eculizumab) with a favorable outcome similar to our patient (10).

Three clinical trials (CORIMUNO19-ECU; NCT04355494; and NCT04369469.) have been initiated, as well as an expanded access program (NCT04288713) to determine if COVID-19 patients treated with a terminal complement inhibitor have a better outcome or less clinical complications than patients who received standard of care.

\section{ACKNOWLEDGMENTS}

The authors would like to thank F. Javier Martín MD. for his work in the emergency room, and Scott Rottinghaus and Kenneth Pomerantz for contributions to the overall study.

\section{BIBLIOGRAPHY}

1. Muntañola A, Villacampa G, Hernández-Rivas JA, et al. Clinical characteristics and outcome of SARS-CoV-2 infection in admitted patients with chronic lymphocytic leukemia from a single European country. Exp Hematol Oncol 2020; 9: 37. doi 10.1186540164-020-00195-x

2. Kulasekararaj AG, Hill A, Rottinghaus ST, et al. Ravulizumab (ALXN1210) vs eculizumab in C5-inhibitor-experienced adult patients with PNH: the 302 study. Blood. 2019; 133(6): 540-549.

3. Cheng Z, Shan J. 2019 Novel coronavirus: where we are and what we know. Infection. 2020;48(2):155-163

4. Mehta P, McAuley D, Brown M, Sanchez E, Tattersall R, Manson J. COVID-19: consider cytokine storm syndromes and immunosuppression. Lancet. $2020 ; 395(10229): 1033-1034$.
5. Zhang Z, Fan H, Jiang M, Zeng Y, Qiu X, Yang C. Coronavirus disease 2019: a clinical review. Eur Rev Med Pharmacol Sci. 2020; 24: 4585-4596.

6. Gralinski, Sheahan TP, Morrison TE, et al. Complement activation contributes to severe acute respiratory syndrome coronavirus pathogenesis. mBio 2018; 9: e01753-18.

7. Diurno F, Numis FG, Porta G, et al. Eculizumab treatment in patients with COVID-19: preliminary results from real life ASL Napoli 2 Nord Experience. Eur Rev Med Pharmacol Sci. 2020; 24(7):40404047.

8. Giudice V, Pagliano P, Vatrella A, Masullo A, Poto $\mathrm{S}$, Polverino BM. Combination of ruxolitinib and eculizumab for treatment of severe SARS-CoV2-related acute respiratory distress syndrome: A Controlled Study. Front Pharmacol. 05 June 2020. https://doi.org/10.3389/fphar.2020.00857

9. McKeage K. Ravulizumab: First Global Approval. Drugs. $2019 ; 79(3): 347-352$.

10. Kulasekararaj A, Lazana I, Large J et al. Terminal complement inhibition dampens the inflammation during COVID-19. Br J Haematol. 2020; doi:10.1111/bjh.16916.

\section{CONFLICT OF INTEREST STATEMENT}

F.A.G. have received honoraria and consulting fees from Alexion Pharmaceuticals, Inc.
If you want to quote our article: Estival P.

SARS-CoV-2 Infection in a patient with paroxysmal nocturnal haemoglobinuria ANALES RANM [Internet]. Real Academia Nacional de Medicina de España; An RANM - Año 2020 • número 137 (03) · páginas 281 - 285 DOI: 10.32440/ar.2020.137.03.cc01 